\title{
Particles Containing Cells as a Strategy to Promote Remyelination in Patients With Multiple Sclerosis
}

\author{
Jorge Matías-Guiu 1,2, Jordi A. Matías-Guiu ', Paloma Montero-Escribano ${ }^{1}$, \\ Juan A. Barcia ${ }^{3}$, Alejandro A. Canales-Aguirre ${ }^{4}$, Juan C. Mateos-Diaz ${ }^{5}$ and \\ Ulises Gómez-Pinedo ${ }^{2 *}$
}

\begin{abstract}
${ }^{1}$ Department of Neurology, Institute of Neurosciences, IdISSC, Hospital Clínico San Carlos, Universidad Complutense de Madrid, Madrid, Spain, ${ }^{2}$ Laboratory of Neurobiology, Institute of Neurosciences, IdISSC, Hospital Clínico San Carlos, Universidad Complutense de Madrid, Madrid, Spain, ${ }^{3}$ Department of Neurosurgery, Institute of Neurosciences, IdISSC, Hospital Clínico San Carlos, Universidad Complutense de Madrid, Madrid, Spain, ${ }^{4}$ Unidad de Evaluación Preclínica, Unidad de Biotecnología Médica y Farmacéutica, Centro de Investigación y Asistencia en Tecnología y Diseño del Estado de Jalisco, Guadalajara, Mexico, ${ }^{5}$ Biotecnología Industrial, Centro de Investigación y Asistencia en Tecnología y Diseño del Estado de 12 Jalisco, CIATEJ, Zapopan, Mexico
\end{abstract}

\section{OPEN ACCESS}

Edited by:

Bruno Stankoff,

Sorbonne Universités, France

Reviewed by:

Brahim Nait Oumesmar,

INSERM U1127 Institut du Cerveau et de la Moelle épinière (ICM), France Andre Ortlieb Guerreiro Cacais,

Karolinska Institutet (KI), Sweden

*Correspondence:

Ulises Gómez-Pinedo

u.gomez.pinedo@gmail.com

Specialty section

This article was submitted to

Multiple Sclerosis and

Neuroimmunology,

a section of the journal

Frontiers in Neurology

Received: 29 October 2019

Accepted: 28 May 2020

Published: 07 July 2020

Citation:

Matías-Guiu J, Matías-Guiu JA, Montero-Escribano P, Barcia JA, Canales-Aguirre AA, Mateos-Diaz JC and Gómez-Pinedo U (2020) Particles

Containing Cells as a Strategy to

Promote Remyelination in Patients

With Multiple Sclerosis.

Front. Neurol. 11:638.

doi: 10.3389/fneur.2020.00638
The repair of demyelinated lesions is a key objective in multiple sclerosis research. Remyelination fundamentally depends on oligodendrocyte progenitor cells (OPC) reaching the lesion; this is influenced by numerous factors including age, disease progression time, inflammatory activity, and the pool of OPCs available, whether they be NG2 cells or cells derived from neural stem cells. Administering OPCs has been proposed as a potential cell therapy; however, these cells can only be administered directly. This article discusses the potential administration of OPCs encapsulated within hydrogel particles composed of biocompatible biomaterials, via the nose-to-brain pathway. We also discuss conditions for the indication of this therapy, and such related issues as the influence on endogenous remyelination, migration of OPCs to demyelinated areas, and the immune response, given the autoimmune nature of multiple sclerosis. Chitosan and derivatives constitute the most promising biomaterial for this purpose, although these issues must be addressed. In conclusion, this line of research may yield an alternative to the remyelinating drugs currently being studied.

Keywords: multiple sclerosis, biomaterials, oligodendrocyte progenitor cells, oligodendrocytes, demyelination, remyelination

\section{INTRODUCTION}

Multiple sclerosis (MS) is a chronic, inflammatory, autoimmune disease in which an environment inhibiting the development of myelin-producing cells hinders repair of the myelin sheaths around demyelinated axons. Demyelination alters the conduction of neural impulses; impairment of the capacity for remyelination results in axonal degeneration, eventually leading to neuronal degeneration (1). Despite the development in recent years of numerous drugs targeting the immune mechanisms that cause inflammation, which has reduced the risk of sequelae, no drug has been found that promotes myelin repair; therefore, a central objective in current research is to design novel therapeutic strategies for remyelination $(2,3)$. 
Despite widely held opinion, the central nervous system (CNS) does have the capacity for remyelination, which has been observed in histopathological analysis of MS plaques and through neuroimaging (4-6); however, the sheaths produced can be thinner than normal, and sequelae and symptoms arising from conduction alterations are not prevented (7). This remyelination capacity is reduced or lost with age; while it is observed in early stages of relapsing-remitting MS, it is much diminished in the progressive stage of the disease. It therefore shows an inverse relationship with MS progression, and has been associated with immune activity (8) and with alterations to innate and adaptive immunity, which are reported to reduce the effectiveness of remyelination in animal models of focal demyelination; myelin repair depends on the state of activation of macrophages and microglia (9). Remyelination capacity is lost without a reduction in the number of oligodendrocyte progenitor cells (OPC), although there is a reduction in the efficiency of OPC differentiation into myelin-producing oligodendrocytes (OL) (10). In theory, effective remyelination requires: [1] the presence of OPCs in demyelinated plaques, through migration to the area of the active lesion; [2] an environment favoring OPC differentiation into OLs; [3] axons in suitable conditions for remyelination (i.e., not undergoing or having undergone a process of neurodegeneration); and [4] action of a series of signaling pathways enabling differentiation by altering OPCs, OLs, and axons in order to enable myelin production by OLs (11-14). However, several studies suggest that remyelination is not always necessary to the survival of demyelinated axons (15). The combination of both benefits may therefore be necessary to maximize the therapeutic potential of OPCs for application in clinical practice.

Work of the lasts decades past century, have explored implant tissue and oligodendrocytes, pioneering cell therapy, as a resource to promote remyelination and the search for the best cell type for this purpose $(16,17)$. Several types of cells can act as OPCs, but we should fundamentally consider 2 cell subtypes: NG2 cells, originating in embryonic development and usually located in the cortex; and those differentiated from adult neural stem cells (NSC) (18), which are found in the subventricular zone and adjacent to the corpus callosum, for example. The OPC population is heterogeneous and specific to particular brain regions, with remyelination efficiency depending on the origin of the OPCs (19). In the search for therapeutic strategies for remyelination, increasing attention has been paid to the potential role of OPCs. Transplantation offers several potential benefits: remyelination by the transplanted cells, stabilization of the demyelinated area, promotion of endogenous remyelination, and a potential neuroprotective mechanism involving growth factors secreted by the transplanted OPCs.

\section{USE OF UNDIFFERENTIATED NEURAL STEM CELLS TO REPAIR MULTIPLE SCLEROSIS LESIONS}

NSCs can differentiate into neurons, astrocytes, and OLs. It has been suggested that they may be used to repair CNS lesions. Implantation of these cells has been shown to have beneficial effects on spinal cord lesions in rodent and primate models, supporting the use of the technique to treat MS (20). Nonetheless, the fact that MS is an autoimmune disease means that these cells' capacity to trigger immunogenicity is a significant consideration, which has led to a search for alternatives including the use of induced pluripotent stem cells (iPSC) (21). However, these cells frequently present genetic modifications, including aberrant DNA methylation and gene mutations, and it has been suggested that their use may lead to tissue aberrations or malignant transformation after transplantation $(22,23)$. The use of iPSCs bypasses ethical issues associated with embryonic or fetal stem cells, as they are generated from non-pluripotent cells. Another means of obtaining undifferentiated cells is the use of directly reprogrammed NSCs, which are generated from somatic cells and seem to be a safer alternative $(24,25)$. However, these cells appear inefficient in promoting remyelination in patients with MS, as only a small percentage of the NSCs grafted differentiate into OLs. One proposal to avoid this problem is the use of partially differentiated cells, such as bipotent glial cells capable of differentiating either into astrocyte or OL lineage cells, or OPCs, which are unipotent and can only differentiate into OLs. OPCs can be derived both from iPSCs $(21,26,27)$ and from directly reprogrammed NSCs (28). Some researchers have even attempted to develop modified OPCs with an improved myelinogenic capacity.

Most evidence on the transplantation of OL lineage cells is from models of traumatic spinal cord lesions. These cells have been shown to be capable of promoting tissue repair and functional recovery $(29,30)$, with one study reporting that the implantation increased the number of OLs, resulting in improved motor function (31). While the mechanism behind this functional improvement is not known, it has been suggested that it may involve neurotrophic factors secreted by OPCs (32). OLs are highly susceptible to reduced survival due to the local cytotoxic conditions in and near immune and traumatic lesions. It has been reported that laboratory pre-differentiation of OL lineage cells and grafting of OPCs is more efficient for remyelinationmediated repair than the grafting of undifferentiated cells (33), particularly if the OPCs are enriched (34); this is a long process, however (35). The generation of OPCs from iPSCs is a recent development (36-38); other researchers have developed cell lines overexpressing such receptors as GPR17, promoting migration (39), or secreting platelet-derived growth factor-AA and fibroblast growth factor-2, favoring proliferation (40).

Human OPCs are known to promote remyelination (41), which has led to the use of various protocols in patients with spinal cord lesions (27, 31, 40-43), achieving an efficiency of differentiation into OLs of $40 \%$ of grafted cells. Administration of OPCs is also effective in rats with congenital hypomyelination (44) and stroke with white matter lesions (45). Research has shown that delayed cell transplantation is effective for older spinal cord lesions (46). The works of Prof Goldman's group highlight the potential of cell therapy in demyelinating pathologies, including those of genetic substrate $(16,47)$.

Most studies into cell therapies for MS do not use NSCs, as they aim to control the autoimmune mechanism rather 
than to promote remyelination. One proposed treatment is the transplantation of different cell types, including human embryonic cells, mesenchymal stem cells derived from human bone marrow (48), human placental stem cells (49), hematopoietic stem cells, human dental pulp stem cells (50), Wharton's jelly-derived stem cells (51), and undifferentiated adipose-derived stem cells (52); these cells have anti-inflammatory and immunomodulatory properties and can reduce degeneration in experimental autoimmune encephalomyelitis (53). However, the issue becomes more complex when we consider the efficiency of implantation in vivo (54) and whether the ability to promote myelin repair (55) owes more to the stimulation of an endogenous repair response or to the cells implanted and their neurotrophic function. These cells also promote remyelination and significantly reduce clinical signs of MS in an animal model of the disease. The most suitable route of administration is subject to debate. NSCs administered intravenously appear in the brain and spinal cord, proliferate, and migrate to MS lesions, probably due to chemotactic mechanisms (56). These findings were reported in various clinical trials, which are addressed in a recent review (57). OPCs, on the other hand, are able to migrate within the CNS but not from the cerebrospinal fluid or the bloodstream; therefore, the route of delivery is an important question if we have to use these cells as a treatment. One possibility is the nose-to-brain pathway, which has been used to administer drugs (58) and nanoparticles (59).

\section{BIOMATERIALS IN CELL THERAPY}

Biomaterials (BM) are natural or synthetic biocompatible materials used in the manufacture of devices that interact with biological systems. BMs are widely used in medicine. Applications include natural or synthetic polymers, used to treat wounds; drug delivery systems; vascular grafts; and tissue reconstruction (60). As well as being biocompatible, it is essential that BMs do not provoke adverse reactions after implantation, and that they continue functioning for the necessary period of time; this need has given rise to efforts to develop products with specific physical and chemical properties. For example, a BM may promote cell development and differentiation by creating a suitable local environment, improving the implanted cells' chances of survival (61). In the administration of OPCs to patients with MS, BMs may serve several purposes, enabling delivery of OPCs to the CNS and promoting migration to demyelinated areas, if they favor differentiation into OLs; nanofiber scaffolds resembling the natural structure of axons enable modeling of the interaction between axons and OLs, promoting neuron-glia interaction and myelination $(62,63)$. The use of biomaterials as particles is one of the most promising approaches. Particles constitute a transport system made up of natural or artificial polymers, enabling controlled, sustained delivery; specific targeting of lesions; and a high surface-areato-volume ratio. This enables drugs to be administered at lower doses and frequency. Given these properties, particles may be the most suitable means of transporting cells (64).

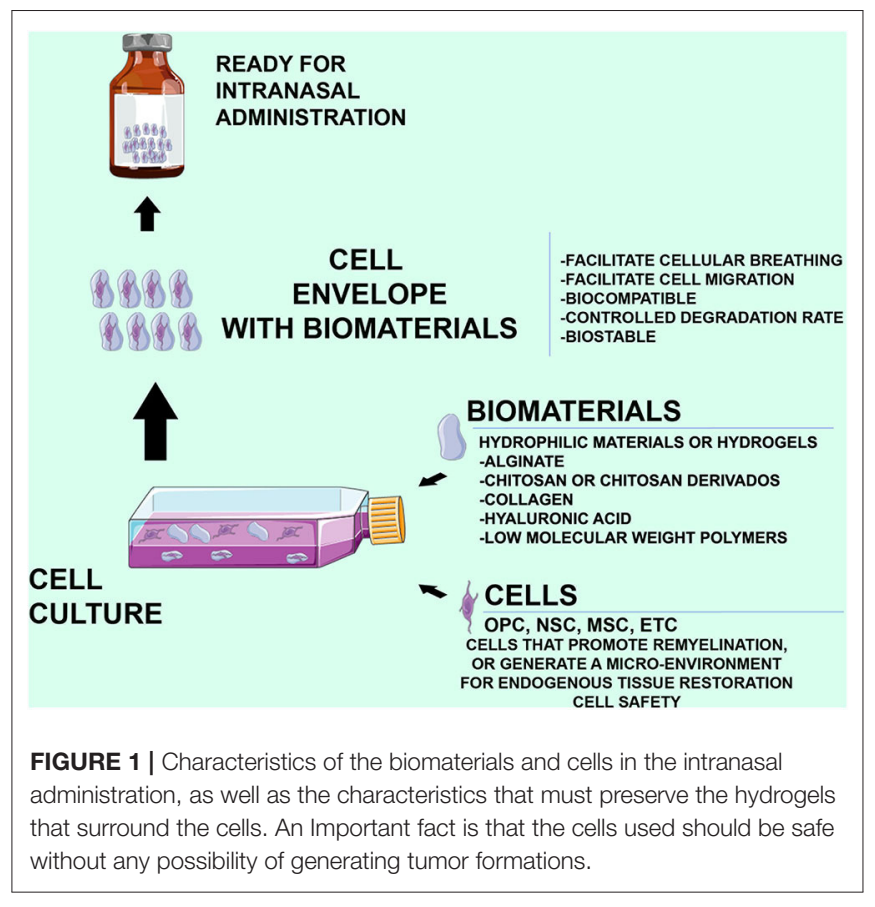

The specific BM chosen for cell therapy is an important factor, as the BM's surface properties are directly related to its biological behavior in vitro (e.g., adherence and the ability to permit cell proliferation and differentiation). Various natural materials, synthetic polymers, and ceramics have been proposed. Natural materials including purified collagen, hyaluronic acid, alginate, and chitosan have been used extensively in regenerative medicine and tissue engineering. Synthetic polymers are reproducible and can be modified to control their properties, such as degradation speed, mechanical properties, and shape. Calcium phosphate ceramics have been used in cell therapy for the skeletal system. Hydrogels constitute a particularly attractive class of materials (65). Hydrogels are networks of polymers, structured in a chemical or physical form, that expand in water and can be designed either with natural materials, such as alginate, or with synthetic polymers including polyethylene glycol. The specific advantages of these materials are the minimal adverse reactions in the host (i.e., biocompatibility), their high water content, the relatively mild reaction conditions, and the capacity for minimally invasive delivery as injectable vehicles. In the Figure 1, shows the characteristics that the cells, the biomaterials, as well as the attributes of the cells wrapped by biomaterials should have (Figure 1), acting as a fine wrap, to facilitate its release.

\section{ISSUES RELATED TO THE ADMINISTRATION OF OPCS THROUGH PARTICLES TO PROMOTE REMYELINATION}

OPCs clearly merit consideration as a therapeutic option targeting remyelination in MS, with the delivery of exogenous 
OPCs to demyelinated areas; however, there remain several outstanding issues (66). Many of these are addressed in an extensive review published recently by Unal et al. (67). Firstly, the most eligible patients are those with reduced remyelinating ability, specifically older patients or those with history of arterial hypertension (68), longer progression times, predominantly periventricular rather than subcortical lesions (periventricular lesions show lower levels of spontaneous remyelination), greater inflammatory activity (as measured with T2-weighted MRI studies), greater numbers of demyelinated areas (black holes on T1-weighted sequences) or larger areas of myelin loss (white matter PET scan) $(69,70)$, or pseudotumoral lesions that may hinder OPC migration (71). Additional relevant questions are: are exogenous OPCs sensitive to mechanisms regulating oligodendrogenesis, or do they behave in the same way as endogenous OPCs? Should chemical products be added to grafts as signals promoting remyelination? What effect does the coexistence of both endogenous and exogenous OPCs have on remyelination? Should the administration of OPCs be different in each patient, in accordance with the degree of demyelination/remyelination?

One important issue is the delivery of OPCs to the CNS and their migration to the lesion area. OPCs can only enter the CNS through direct delivery or through the nose-to-brain pathway, which is only possible if they are loaded into particles capable of crossing the nasal mucosa. Cells administered by this route travel directly to the CNS, with minimal loss to other regions (72). Particles should allow for migration to the lesion site and differentiation into OLs.

\section{INTRANASAL RUTE}

The basis of the mechanism of intranasal delivery is not understood, existent four main routes: [1] olfactory nerves, [2] trigeminal nerve pathway, [3] Lymphatic pathway, and [4] vascular pathways. Previously mentioned, the movement of molecules from the nasal cavity to the parenchyma of the brain occurs along both the nerve pathways (olfactory or trigeminal nerves) mainly, followed by vascular and lymphoid pathways. Dispersing throughout the brain, even reaching up to the cerebrospinal fluid (73). Two mechanisms are involved in this distribution: extracellular (used to transport large molecules and cells) and intracellular (used to transport by retrograde flow, small molecules, drugs, vectors, trophic factors, etc.). The extracellular pathway begins with the drug or cells crossing the nasal epithelium to the lamina propria, before being transported externally along the length of the neuronal axon by bulk flow processes. The axon leads into the CNS, where the drug or cells is distributed further via fluid movement. The intracellular mechanism starts with internalization of the molecule by an olfactory neuron, with the endocytic vesicle within the cell to the neuron's projection site (soma), it can be released by exocytosis or have its effect on the transport cell $(74,75)$.

Various materials have been used in the intranasal administration of drugs, vaccines or exosomes. In the
Supplementary Material 1, a table is shown with the materials used in the intranasal administration of substances.

\section{NASAL ADMINISTRATION OF CHITOSAN}

Chitosan and its derivatives seem to be the most suitable natural polymers for administration to the CNS (76). Chitosan is a mucopolysaccharide closely resembling cellulose, produced during the deacetylation of chitin. It is derived from the shells of crustaceans and from fungal cell walls (77). Chitosan particles are biodegradable, biocompatible, and stable, with low toxicity, and are soluble in aqueous acid solutions $(78,79)$. While many routes of administration are available (80), nasal administration allows passage to the brain (81), and has been used for such drugs as anti-LINGO-1 (82), teriflunomide (83), and carbamazepine (84). Nasal administration of chitosan hydrogel has been used as a treatment for Alzheimer disease or biomedical applications in the CNS $(85,86)$. While there is less evidence on the transportation of cells than there is for drugs, chitosan is known to permit differentiation of both NSCs (87) and OPCs (88). Chitosan appears to be particularly appropriate for administration via the nose-to-brain pathway $(89,90)$. This route of administration is particularly attractive for the delivery of drugs to the CNS, as it bypasses the blood-brain barrier (91-93). The nasal cavity is connected to the brain via the olfactory and trigeminal pathways (94), enabling administration of drugs through the nasal mucosa (90). This is a painless, non-invasive means of administration and can be used to deliver therapeutic agents in patients with neurodegenerative diseases (95-99). Furthermore, drugs delivered through the nasal mucosa are not subject to hepatic first pass metabolism. Therefore, doses are usually 2-10 times lower if drugs are administered nasally rather than orally.

Up to one-third of patients with MS present olfactory alterations, although these are generally detected through physical examination rather than because of patients' complaints. Such alterations are attributed to changes in the connectivity of various CNS pathways, and are more frequently observed in patients with progressive forms of MS and with cognitive alterations (100); therefore, they should not affect the passage of particles to the brain.

If chitosan is to be used in treatments for MS, an autoimmune disease, we must consider whether the material provokes an immune response or triggers any kind of response favoring autoimmunity. However, chitosan has been used as a component of a vehicle for oral interferon beta in patients with MS (101), and for the administration of vaccines (102). It is also difficult to attribute immune responses exclusively to chitosan, as the products transported in the particles may themselves provoke such a reaction. Studies have shown that the treatment may provoke an innate (103) and adaptive immune response (104106), although increased levels of anti-inflammatory cytokines have also been reported (107). Several syntethic polymers or natural biomaterials have been used for CNS applications, chitosan is nowadays one of the leading substrates, employed as it can be found in nature or as a modified derivative. In biomolecules delivery, it stands out for its mucoadhesive 


\section{EXPERIMENTAL STAGES}

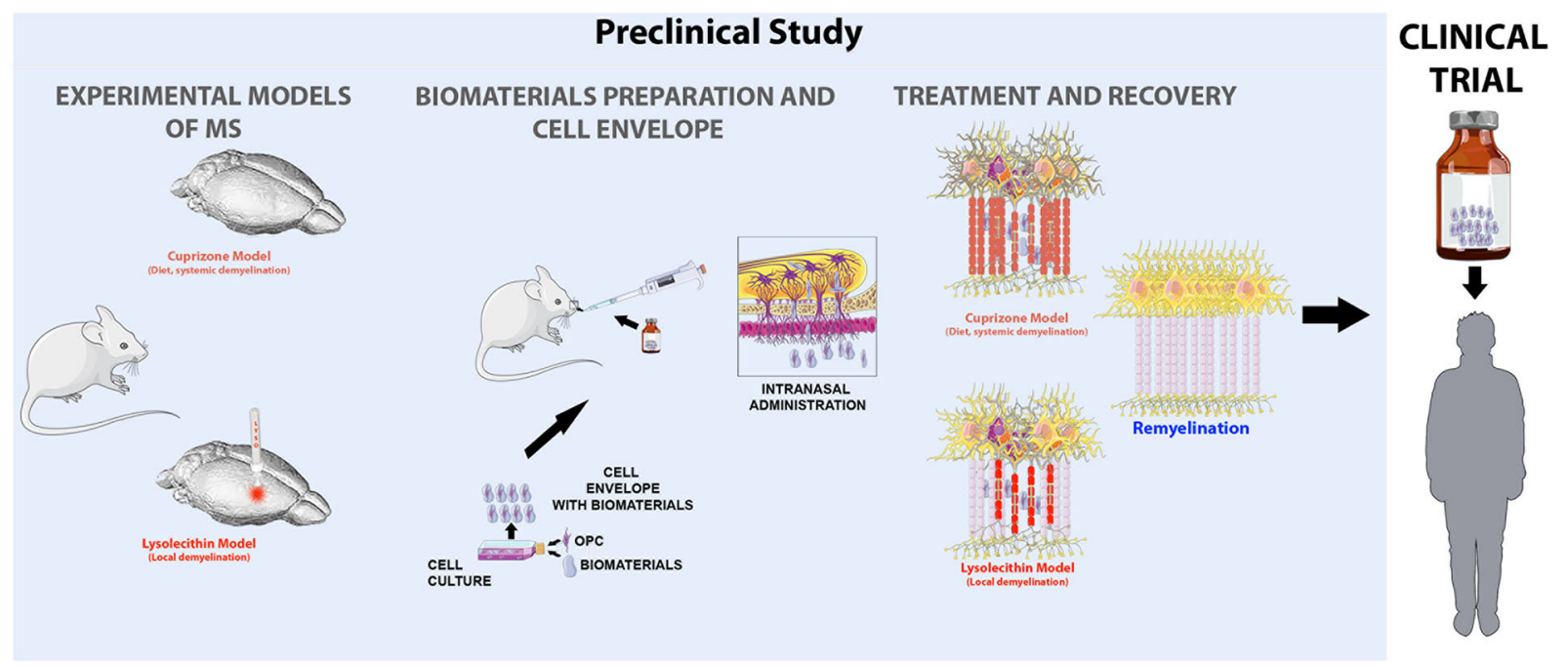

FIGURE 2 | Experimental scheme proposed as a strategy to evaluate the viability of intranasal administration of cells in two models of multiple sclerosis, the cupriazone model (administered in the diet for 5 weeks) which is a systematic demyelination and the lysolecithin model, the which by means of the amplification by sterotactic injection in the corpus callosum of the animals induces foci of local demyelination. Where the main objective of our hypothesis is to achieve the activation of endogenous remyelination mechanisms in the central nervous system, favored by the application of myelinating cells wrapped in biocompatible biomaterials that preserve cell characteristics and allow to generate a favorable microenvironment.

and $\mathrm{BBB}$ penetration enhancement properties that make it a great substrate for nose-to-brain approaches $(76,86,97)$. For tissue engineering and regenerative medicine, chitosan and its derivatives have shown to promote axonal regeneration, antiinflammation, and to successful deliver neurotrophic factors and cells with a consequently functional recovery (108). In this way, chitosan-based biomaterials have become increasingly popular to use, alone or in combination with other molecules (86).

In the Figure 2, shows in a schematic and simple way the stages in the development of the project, starting from the preclinical trial to the clinical trial (Figure 2).

\section{CONCLUSIONS}

While the potential use of OPCs for remyelination is a promising therapeutic strategy, there is a need for basic research before clinical trials can be performed. It is also necessary to establish the best route of administration, although transporting cells in particles through the nose-to-brain pathway seems the most suitable. Researchers must also assess which BM is most appropriate; while chitosan and derivatives seem to be the most promising, we must assess the responses of patients with MS and whether migration to demyelinated areas is maintained. In conclusion, this line of research may yield an alternative to the remyelinating drugs currently being studied.

Studies should take into account various additional problems, including immune response to the treatment, given that MS is an autoimmune disease, and the use of associated immunomodulatory treatments. Treatment with repeated intracerebral injections of increasing doses of OPCs to different locations has been proposed as a treatment for patients with secondary-progressive MS. However, this method is not straightforward, given the need for administration protocols guaranteeing reproducibility and reducing the considerable rate of cell death associated with transplantation via injection; the survival rate can reach $1 \%$ due to such factors as exposure of cells to an inflammatory microenvironment, limited diffusion of oxygen and nutrients, immune destruction, dispersion through a deteriorated local vascular system, and activation of apoptosis and autophagy.

\section{AUTHOR CONTRIBUTIONS}

JM-G and UG-P: lead researchers. All authors: manuscript drafting, research project group, and critical review of the manuscript.

\section{ACKNOWLEDGMENTS}

We wish to thank the Spanish Society of Neurology's Research Operations Office for their help with the translation of the manuscript.

\section{SUPPLEMENTARY MATERIAL}

The Supplementary Material for this article can be found online at: https://www.frontiersin.org/articles/10.3389/fneur. 2020.00638/full\#supplementary-material

Table 1 Materials used in intranasal administration, show their topical form (spay, particles, gel) and the therapeutic strategy. 


\section{REFERENCES}

1. Nave KA, Trapp BD. Axon-glial signaling and the glial support of axon function. Annu Rev Neurosci. (2008) 31:53561. doi: 10.1146/annurev.neuro.30.051606.094309

2. Wootla B, Watzlawik JO, Denic A, Rodriguez M. The road to remyelination in demyelinating diseases: current status and prospects for clinical treatment. Exp Rev Clin Immunol. (2013) 9:535-49. doi: 10.1586/eci.13.37

3. Matías-Guiu J, Gomez-Pinedo U, Matias-Guiu JA. News in multiple sclerosis: remyelination as a therapeutic target. Med Clin. (2017) 148:37780. doi: 10.1016/j.medcle.2017.04.008

4. Staugaitis SM, Chang A, Trapp BD. Cortical pathology in multiple sclerosis: Experimental approaches to studies on the mechanisms of demyelination and remyelination. Acta Neurol Scand. (2012) 195:97102. doi: 10.1111/ane.12041

5. Brown RA, Narayanan S, Arnold DL. Segmentation of magnetization transfer ratio lesións for longitudinal analysis of demyelination and remyelination in multiple sclerosis. Neuroimage. (2012) 66:103-9. doi: 10.1016/j.neuroimage.2012.10.059

6. Franklin RJ, ffrench-Constant C, Edgar JM, Smith KJ. Neuroprotection and repair in multiple sclerosis. Nat Rev Neurol. (2012) 8:624-34. doi: 10.1038/nrneurol.2012.200

7. Ludwin SK, Maitland M. Long-term remyelination fails to reconstitute normal thickness of central myelin sheaths. J Neurol Sci. (1984) 64:1938. doi: 10.1016/0022-510X(84)90037-6

8. Hagemeier K, Bruck W, Kuhlmann T. Multiple sclerosis-remyelination failure as a cause of disease progression. Histol Histopathol. (2012) 27:27787. doi: 10.14670/HH-27.277

9. El Behi M, Sanson C, Bachelin C, Guillot-Noël L, Fransson J, Stankoff B, et al. Adaptive human immunity drives remyelination in a mouse model of demyelination. Brain. (2017) 140:967-80. doi: 10.1093/brain/awx008

10. Kipp M, Victor M, Martino G, Franklin RJ. Endogeneous remyelination: findings in human studies. CNS Neurol Disord Drug Targets. (2012) 11:598609. doi: 10.2174/187152712801661257

11. Jepson S, Vought B, Gross CH, Gan L, Austen D, Frantz JD, et al. LINGO-1, a transmembrane signaling protein, inhibits oligodendrocyte differentiation and myelination through intercellular self-interactions. J Biol Chem. (2012) 287:22184-95. doi: 10.1074/jbc.M112.366179

12. Schmidt F, van den Eijnden M, Pescini Gobert R, Saborio GP, Carboni $\mathrm{S}$, Alliod C, et al. Identification of VHY/Dusp15 as a regulator of oligodendrocyte differentiation through a systematic genomics approach. PLoS One. (2012) 7:e40457. doi: 10.1371/journal.pone.0040457

13. Deshmukh VA, Tardif V, Lyssiotis CA, Green CC, Kerman B, Kim HJ, et al. A regenerative approach to the treatment of multiple sclerosis. Nature. (2013) 502:327-32. doi: 10.1038/nature12647

14. Zuchero JB, Barres BA. Intrinsic and extrinsic control of oligodendrocyte development. Cur Op Neurobiol. (2013) 23:914-20. doi: 10.1016/j.conb.2013.06.005

15. Smith CM, Cooksey E, Duncan ID. Myelin loss does not lead to axonal degeneration in a long-lived model of chronic demyelination. J Neurosci. (2013) 33:2718-27. doi: 10.1523/JNEUROSCI.4627-12.2013

16. Steven A. Goldman. Progenitor cell-based treatment of glial disease. Prog Brain Res. (2017) 231:165-89. doi: 10.1016/bs.pbr.2017.02.010

17. Windrem MS, Nunes MC, Rashbaum WK, Schwartz TH, Goodman RA, McKhann G 2nd, et al. Fetal and adult human oligodendrocyte progenitor cell isolates myelinate the congenitally dysmyelinated brain. Nat Med. (2004) 10:93-7. doi: 10.1038/nm974

18. Gómez-Pinedo U, Sirerol-Piquer MS, Durán-Moreno M, García-Verdugo JM, Matias-Guiu J. Alexander disease mutations produce cells with coexpression of glial fibrillary acidic protein and NG2 in neurosphere cultures and inhibit differentiation into mature oligodendrocytes. Front Neurol. (2017). 8:255. doi: 10.3389/fneur.2017.00255

19. Vigano F, Mobius W, Gotz M, Dimou L. Transplantation reveals regional differences in oligodendrocyte differentiation in the adult brain. Nat Neurosci. (2013) 16:1370-2. doi: 10.1038/nn.3503

20. Ben-Hur T. Cell therapy for multiple sclerosis. Neurotherapeutics. (2011) 8:625-42. doi: 10.1007/s13311-011-0073-X
21. Nori S, Okada Y, Yasuda A, Tsuji O, Takahashi Y, Kobayashi Y, et al. Grafted human-induced pluripotent stem-cell-derived neurospheres promote motor functional recovery after spinal cord injury in mice. Proc Natl Acad Sci USA. (2011) 108:16825-30. doi: 10.1073/pnas.1108077108

22. Yu DX, Marchetto MC, Gage FH. Therapeutic translation of iPSCs for treating neurological disease. Cell Stem Cell. (2013) 12:678-88. doi: 10.1016/j.stem.2013.05.018

23. Nori S, Okada Y, Nishimura S, Sasaki T, Itakura G, Kobayashi Y, et al. Longterm safety issues of iPSC-based cell therapy in a spinal cord injury model: oncogenic transformation with epithelial-mesenchymal transition. Stem Cell Rep. (2015) 4:360-73. doi: 10.1016/j.stemcr.2015.01.006

24. Pang ZP, Yang N, Vierbuchen T, Ostermeier A, Fuentes DR, Yang TQ, et al. Induction of human neuronal cells by defined transcription factors. Nature. (2011) 476:220-3. doi: 10.1038/nature10202

25. Hong JY, Lee SH, Lee SC, Kim JW, Kim KP, Kim SM, et al. Therapeutic potential of induced neural stem cells for spinal cord injury. J Biol Chem. (2014) 289:32512-25. doi: 10.1074/jbc.M114.588871

26. Thiruvalluvan A, Czepiel M, Kap YA, Mantingh-Otter I, Vainchtein I, Kuipers J., et al. Survival and functionality of human induced pluripotent stem cell-derived oligodendrocytes in a nonhuman primate model for multiple sclerosis. Stem Cells Transl Med. (2016) 5:155061. doi: 10.5966/sctm.2016-0024

27. Kawabata S, Takano M, Numasawa-Kuroiwa Y, Itakura G, Kobayashi Y, Nishiyama Y, et al. Grafted human iPS cell-derived oligodendrocyte precursor cells contribute to robust remyelination of demyelinated axons after spinal cord injury. Stem Cell Rep. (2016) 6:1-8. doi: 10.1016/j.stemcr.2015.11.013

28. Nagoshi N, Khazaei M, Ahlfors JE, Ahuja CS, Nori S, Wang J, et al. Human spinal oligodendrogenic neural progenitor cells promote functional recovery after spinal cord injury by axonal remyelination and tissue sparing. Stem Cells Transl Med. (2018) 7:806-18. doi: 10.1002/sctm.17-0269

29. Assinck P, Duncan GJ, Hilton BJ, Plemel JR, Tetzlaff W. Cell transplantation therapy for spinal cord injury. Nat Neurosci. (2017) 20:637-47. doi: 10.1038/nn.4541

30. Nagoshi N, Tsuji O, Nakamura M, Okano H. Cell therapy for spinal cord injury using induced pluripotent stem cells. Regen Ther. (2019) 11:7580. doi: 10.1016/j.reth.2019.05.006

31. All AH, Gharibani P, Gupta S, Bazley FA, Pashai N, Chou BK, et al. Early intervention for spinal cord injury with human induced pluripotent stem cells oligodendrocyte progenitors. PLoS One. (2015) 10:e0116933. doi: 10.1371/journal.pone.0116933

32. Rosa PM, Martins LAM, Souza DO, Quincozes-Santos A. Glioprotective effect of resveratrol: an emerging therapeutic role for oligodendroglial cells. Mol Neurobiol. (2018) 55:2967-78. doi: 10.1007/s12035-017-0510-x

33. Kokaia Z, Llorente IL, Carmichael ST. Customized brain cells for stroke patients using pluripotent stem cells. Stroke. (2018) 49:10918. doi: 10.1161/STROKEAHA.117.018291

34. Umebayashi D, Coles B, van der Kooy D. Enrichment of oligodendrocyte progenitors from differentiated neural precursors by clonal sphere preparations. Stem Cells Dev. (2016) 25:712-28. doi: 10.1089/scd.2015.0244

35. Kim DS, Jung SJ, Lee JS, Lim BY, Kim HA, Yoo JE, et al. Rapid generation of OPC-like cells from human pluripotent stem cells for treating spinal cord injury. Exp Mol Med. (2017) 49:e361. doi: 10.1038/emm.2017.106

36. Najm FJ, Lager AM, Zaremba A, Wyatt K, Caprariello AV, Factor DC, et al. Transcription factor-mediated reprogramming of fibroblasts to expandable, myelinogenic oligodendrocyte progenitor cells. Nat Biotechnol. (2013). 31:426-33. doi: 10.1038/nbt.2561

37. Yang N, Zuchero JB, Ahlenius H, Marro S, Ng YH, Vierbuchen T, et al. Generation of oligodendroglial cells by direct líneage conversion. Nat Biotechnol. (2013). 31:434-9. doi: 10.1038/nbt.2564

38. Lee EH, Park $\mathrm{CH}$. Comparison of reprogramming methods for generation of induced-oligodendrocyte precursor cells. Biomol Ther. (2017) 25:3626. doi: 10.4062/biomolther.2017.066

39. Bonfanti E, Gelosa P, Fumagalli M, Dimou L, Viganò F, Tremoli $\mathrm{E}$, et al. The role of oligodendrocyte precursor cells expressing the GPR17 receptor in brain remodeling after stroke. Cell Death Dis. (2017) 8:e2871. doi: 10.1038/cddis.2017.256 
40. Yao ZF, Wang Y, Lin YH, Wu Y, Zhu AY, Wang R, et al. Transplantation of PDGF-AA-Overexpressing oligodendrocyte precursor cells promotes recovery in rat following spinal cord injury. Front Cell Neurosci. (2017) 11:79. doi: 10.3389/fncel.2017.00079

41. Keirstead HS, Nistor G, Bernal G, Totoiu M, Cloutier F, Sharp K, et al. Human embryonic stem cell-derived oligodendrocyte progenitor cell transplants remyelinate and restore locomotion after spinal cord injury. $J$ Neurosci. (2005) 25:4694-705. doi: 10.1523/JNEUROSCI.0311-05.2005

42. Manley NC, Priest CA, Denham J, Wirth ED III, Lebkowski JS. Human embryonic stem cell-derived oligodendrocyte progenitor cells: preclinical efficacy and safety in cervical spinal cord injury. Stem Cells Trans Med. (2017) 6:1917-29. doi: 10.1002/sctm.17-0065

43. Priest CA, Manley NC, Denham J, Wirth ED III, Lebkowski JS. Preclinical safety of human embryonic stem cell-derived oligodendrocyte progenitors supporting clinical trials in spinal cord injury. Reg Med. (2015) 10:93958. doi: $10.2217 /$ rme. 15.57

44. Wang J, Chao F, Han F, Zhang G, Xi Q, Li J, et al. Pet demonstrates functional recovery after transplantation of induced pluripotent stem cells in a rat model of cerebral ischemic injury. J Nucl Med. (2013) 54:78592. doi: 10.2967/jnumed.112.111112

45. Yu X, Wu H, Zhao Y, Guo Y, Chen Y, Dong $\mathrm{P}$, et al. Bone marrow mesenchymal stromal cells alleviate brain white matter injury via the enhanced proliferation of oligodendrocyte progenitor cells in focal cerebral ischemic rats. Brain Res. (2018) 1680:127-36. doi: 10.1016/j.brainres.2017.12.019

46. Karimi-Abdolrezaee S, Eftekharpour E, Wang J, Morshead CM, Fehlings MG. Delayed transplantation of adult neural precursor cells promotes remyelination and functional neurological recovery after spinal cord injury. J Neurosci. (2006) 26:3377-89. doi: 10.1523/JNEUROSCI.4184-05.2006

47. Wang S, Bates J, Li X, Chandler-Militello D, Levine C, Maherali N, et al. Human iPSC-derived oligodendrocyte progenitor cells can myelinate and rescue a mouse model of congenital hypomyelination. Cell Stem Cell. (2013) 12:252-64. doi: 10.1016/j.stem.2012.12.002

48. Jin MC, Medress ZA, Azad TD, Doulames VM, Veeravagu A. Stem cell therapies for acute spinal cord injury in humans: a review. Neurosurg Focus. (2019) 46:E10. doi: 10.3171/2018.12.FOCUS18602

49. Freedman MS, Bar-Or A, Atkins HL, Karussis D, Frassoni F, Lazarus HM, et al. The therapeutic potential of mesenchymal stem cell transplantation as a treatment for multiple sclerosis: consensus report of the International MSCT study Group. Mult Scler. (2010) 16:503-10. doi: 10.1177/1352458509359727

50. Askari N, Yaghoobi MM, Shamsara M, Esmaeili-Mahani S. Human dental pulp stem cells differentiate into oligodendrocyte progenitors using the expression of Olig2 transcription factor. Cells Tissues Organs. (2015) 200:93103. doi: $10.1159 / 000381668$

51. Mikaeili Agah E, Parivar K, Joghataei MT. Therapeutic effect of transplanted human Wharton's jelly stem cell-derived oligodendrocyte progenitor cells (hWJ-MSC-derived OPCs) in an animal model of multiple sclerosis. $\mathrm{Mol}$ Neurobiol. (2014) 49:625-32. doi: 10.1007/s12035-013-8543-2

52. Constantin G, Marconi S, Rossi B, Angiari S, Calderan L, Anghileri $\mathrm{E}$, et al. Adipose-derived mesenchymal stem cells ameliorate chronic experimental autoimmune encephalomyelitis. Stem Cells. (2009) 27:262435. doi: 10.1002/stem.194

53. Prockop DJ, Oh JY. Mesenchymal stem/stromal cells (MSCs): role as guardians of inflammation. Mol Ther. (2012) 20:1420. doi: $10.1038 / \mathrm{mt} .2011 .211$

54. Windrem MS, Schanz SJ, Guo M, Tian GF, Washco V, Stanwood N, et al. Neonatal chimerization with human glial progenitor cells can both remyelinate and rescue the otherwise lethally hypomyelinated shiverer mouse. Cell Stem Cell. (2008) 2:553-65. doi: 10.1016/j.stem.2008.03.020

55. Gordon D, Pavlovska G, Uney JB, Wraith DC, Scolding NJ. Human mesenchymal stem cells infiltrate the spinal cord, reduce demyelination, and localize to white matter lesións in experimetnal autoimmune encephalomyelitis. J Neuropathol Exp Neurol. (2010) 69:1087-95. doi: 10.1097/NEN.0b013e3181f97392

56. Rice CM, Scolding NJ. Adult human mesenchymal cells proliferate and migrate in response to chemokines expressed in demyelination. Cell Adh Migr. (2010) 4:235-40. doi: 10.4161/cam.4.2.11404
57. Scolding NJ, Pasquini M, Reingold SC, Cohen JA, International Conference on Cell-Based Therapies for Multiple Sclerosis. Cellbased therapeutic strategies for multiple sclerosis. Brain. (2017). 140:2776-96. doi: 10.1093/brain/awx154

58. Schwarz B, Merkel OM. Nose-to-brain delivery of biologics. Ther Deliv. (2019) 10:207-10. doi: 10.4155/tde-2019-0013

59. Sukumar UK, Bose RJC, Malhotra M, Babikir HA, Afjei R, Robinson E, et al. Intranasal delivery of targeted polyfunctional gold-iron oxide nanoparticles loaded with therapeutic microRNAs for combined theranostic multimodality imaging and presensitization of glioblastoma to temozolomide. Biomaterials. (2019) 218:119342. doi: 10.1016/j.biomaterials.2019.119342

60. Aurand ER, Lampe KJ, Bjugstad KB. Defining and designing polymers and hydrogels for neural tissue engineering. Neurosci Res. (2012) 72:199213. doi: 10.1016/j.neures.2011.12.005

61. Sanchez-Rojas L, Gómez-Pinedo U, Benito-Martin MS, León-Espinosa G, Rascón-Ramirez F, Lendinez C, et al. Biohybrids of scaffolding hyaluronic acid biomaterials plus adipose stem cells home local neural stem and endothelial cells: implications for reconstruction of brain lesións after stroke. J Biomed Mater Res B Appl Biomater. (2019) 107:1598606. doi: 10.1002/jbm.b.34252

62. Lee S, Leach MK, Redmond SA, Chong SY, Mellon SH, Tuck SJ, et al. A culture system to study oligodendrocyte myelination processes using engineered nanofibers. Nat Methods. (2012) 9:917-22. doi: 10.1038/nmeth.2105

63. Lee S, Chong SY, Tuck SJ, Corey JM, Chan JR. A rapid and reproducible assay for modeling myelination by oligodendrocytes using engineered nanofibers. Nat Protoc. (2013) 8:771-82. doi: 10.1038/nprot.2013.039

64. Sunena, Singh SK, Mishra DN. Nose to brain delivery of galantamine loaded nanoparticles: in-vivo pharmacodynamic and biochemical study in mice. Curr Drug Deliv. (2019) 16:51-8. doi: 10.2174/1567201815666181004094707

65. Bashir S, Teo YY, Ramesh S, Ramesh K. Synthesis and characterization of karaya gum-g-poly (acrylic acid) hydrogels and in vitro release of hydrophobic quercetin. Polymer. (2018) 147:108-20. doi: 10.1016/j.polymer.2018.05.071

66. Russell LN, Lampe KJ. Engineering biomaterials to influence oligodendroglial growth, maturation, and myelin production. Cells Tissues Organs. (2016). 202:85-101. doi: 10.1159/000446645

67. Unal DB, Caliari SR, Lampe KJ. Engineering biomaterial microenvironments to promote myelination in the central nervous system. Brain Res Bull. (2019). 152:159-74. doi: 10.1016/j.brainresbull.2019.07.013

68. Liang AC, Mandeville ET, Maki T, Shindo A, Som AT, Egawa N, et al. Effects of aging on neural stem/progenitor cells and oligodendrocyte precursor cells after focal cerebral ischemia in spontaneously hypertensive rats. Cell Transplant. (2016) 25:705-14. doi: 10.3727/096368916X690557

69. Matías-Guiu JA, Cabrera-Martín MN, Matías-Guiu J, Oreja-Guevara C, Riola-Parada C, Moreno-Ramos T, et al. Amyloid PET imaging in multiple sclerosis: an (18)F-florbetaben study. BMC Neurol. (2015). 15:243. doi: 10.1186/s12883-015-0502-2

70. Matías-Guiu JA, Oreja-Guevara C, Cabrera-Martín MN, Moreno-Ramos T, Carreras JL, Matías-Guiu J. Amyloid proteins and their role in multiple sclerosis. considerations in the use of amyloid-PET imaging. Front Neurol. (2016) 7:53. doi: 10.3389/fneur.2016.00053

71. Matías-Guiu JA, Cabrera-Martín MN, Cortés-Martínez A, Pytel $\mathrm{V}$, Moreno-Ramos T, Oreja-Guevara C, et al. Amyloid PET in pseudotumoral multiple sclerosis.Mult Scler Relat Disord. (2017). 15:15-17. doi: 10.1016/j.msard.2017.05.002

72. Uchegbu I, Wang Z, Xiong G, Tsang A, Schatzlein A. Nose to brain delivery. J Pharmacol Exp Ther. (2019) 370:593-601. doi: 10.1124/jpet.119.258152

73. Rohrer J, Lupo N, Bernkop-Schnürch A. Advanced formulations for intranasal delivery of biologics. Int $J$ Pharm. (2018) 553:8-20. doi: 10.1016/j.ijpharm.2018.10.029

74. Renner DB, Frey WH 2nd, Hanson LR. Intranasal delivery of siRNA to the olfactory bulbs of mice via the olfactory nerve pathway. Neurosci Lett. (2012) 513:193-7. doi: 10.1016/j.neulet.2012.02.037

75. Jiang $\mathrm{Y}, \mathrm{Zhu} \mathrm{J}, \mathrm{Xu} \mathrm{G}$, Liu $\mathrm{X}$. Intranasal delivery of stem cells to the brain. Expert Opin Drug Deliv. (2011) 8:62332. doi: $10.1517 / 17425247.2011 .566267$ 
76. Yu S, Xu X, Feng J, Liu M, Hu K. Chitosan and chitosan coating nanoparticles for the treatment of brain disease. Int J Pharm. (2019) 560:28293. doi: 10.1016/j.ijpharm.2019.02.012

77. Mohammed MA, Syeda JTM, Wasan KM, Wasan EK. An overview of chitosan nanoparticles and its application in non-parenteral drug delivery. Pharmaceutics. (2017) 9:53. doi: 10.3390/pharmaceutics9040053

78. Pangestuti R, Kim SK. Neuroprotective properties of chitosan and its derivatives. Mar Drugs. (2010) 8:2117-28. doi: 10.3390/md8072117

79. Corbet C, Ragelle H, Pourcelle V, Vanvarenberg K, Marchand-Brynaert J, Preat V, et al. Delivery of siRNA targeting tumor metabolism using noncovalent PEGylated chitosan nanoparticles: identification of an optimal combination of ligand structure, linker and grafting method. J Control Release. (2016) 223:53-63. doi: 10.1016/j.jconrel.2015.12.020

80. Garg U, Chauhan S, Nagaich U, Jain N. Current advances in Chitosan nanoparticles based drug delivery and targeting. Adv Pharm Bull. (2019) 9:195-204. doi: 10.15171/apb.2019.023

81. llum L. Nasal drug delivery-possibilities, problems and solutions. J Control Release. (2003). 87:187-98. doi: 10.1016/S0168-3659(02)00363-2

82. Youssef AEH, Dief AE, El Azhary NM, Abdelmonsif DA, El-Fetiany OS. LINGO-1 siRNA nanoparticles promote central remyelination in ethidium bromide-induced demyelination in rats. J Physiol Biochem. (2019) 75:8999. doi: 10.1007/s13105-018-00660-6

83. Gadhave DG, Kokare CR. Nanostructured lipid carriers engineered for intranasal delivery of teriflunomide in multiple sclerosis: optimization and in vivo studies. Drug Dev Ind Pharm. (2019) 45:839-51. doi: 10.1080/03639045.2019.1576724

84. Liu S, Yang S, Ho PC. Intranasal administration of carbamazepine-loaded carboxymethyl chitosan nanoparticles for drug delivery to the brain. Asían J Pharm Sci. (2018) 13:72-81. doi: 10.1016/j.ajps.2017.09.001

85. Al Harthi S, Alavi SE, Radwan MA, El Khatib MM, AlSarra IA. Nasal delivery of donepezil HCl-loaded hydrogels for the treatment of Alzheimer's disease. Sci Rep. (2019) 9:9563. doi: 10.1038/s41598-019-46032-y

86. Ojeda-Hernández DD, Canales-Aguirre AA, Matias-Guiu J, Gomez-Pinedo U, Mateos-Díaz JC. Potential of Chitosan and its derivatives for biomedical applications in the central nervous system. Front Bioeng Biotechnol. (2020) 8:389. doi: $10.3389 /$ fbioe. 2020.00389

87. $\mathrm{Li} \mathrm{H}$, Koenig $\mathrm{AM}$, Sloan $\mathrm{P}$, Leipzig ND. In vivo assessment of guided neural stem cell differentiation in growth factor immobilized chitosan-based hydrogel scaffolds. Biomaterials. (2014) 35:9049-57. doi: 10.1016/j.biomaterials.2014.07.038

88. Mekhail M, Almazan G, Tabrizian M. Purine-crosslinked injectable chitosan sponges promote oligodendrocyte progenitor cells' attachment and differentiation. Biomater Sci. (2015) 3:279-87. doi: 10.1039/C4BM00215F

89. Piazzini V, Landucci E, D’Ambrosio M, Tiozzo Fasíolo L, Cinci L, Colombo $\mathrm{G}$, et al. Chitosan coated human serum albumin nanoparticles: a promising strategy for nose-to-brain drug delivery. Int J Biol Macromol. (2019) 129:26780. doi: 10.1016/j.ijbiomac.2019.02.005

90. Dalpiaz A, Fogagnolo M, Ferraro L, Capuzzo A, Pavan B, Rassu G, et al. Nasal chitosan microparticles target a zidovudine prodrug to brain HIV sanctuaries. Antiviral Res. (2015). 123:146-57. doi: 10.1016/j.antiviral.2015.09.013

91. Espinoza LC, Vacacela M, Clares B, Garcia ML, Fabrega MJ, Calpena AC. Development of a nasal donepezil-loaded microemulsion for the treatment of Alzheimer's disease: in vitro and ex vivo characterization. CNS Neurol Disord Drug Targets. (2018) 17:43-53. doi: 10.2174/1871527317666180104122347

92. Dhuria SV, Hanson LR, Frey WH. Intranasal delivery to the central nervous system: mechanisms and experimental considerations. J Pharm Sci. (2010) 99:1654-73. doi: 10.1002/jps.21924

93. Pardeshi CV, Belgamwar VS. Direct nose to brain drug delivery via integrated nerve pathways bypassing the blood-brain barrier: an excellent platform for brain targeting. Expert Opin Drug Deliv. (2013) 10:95772. doi: 10.1517/17425247.2013.790887

94. Mistry A, Stolnik S, Illum L. Nanoparticles for direct nose-to-brain delivery of drugs. Int J Pharm. (2009) 379:146-57. doi: 10.1016/j.ijpharm.2009.06.019

95. Yalcin A, Soddu E, Turunc Bayrakdar E, Uyanikgil Y, Kanit L, Armagan G, et al. Neuroprotective effects of engineered polymeric nasal microspheres containing hydroxypropyl- $\beta$-cyclodextrin on $\beta$-Amyloid (1-42)-induced toxicity. J Pharm Sci. (2016) 105:2372-80. doi: 10.1016/j.xphs.2016.05.017

96. Rassu G, Porcu EP, Fancello S, Obinu A, Senes N, Galleri G, et al. Intranasal delivery of genistein-loaded nanoparticles as a potential preventive system against neurodegenerative disorders. Pharmaceutics. (2019) 11:8. doi: 10.3390/pharmaceutics11010008

97. Rassu G, Soddu E, Posadino AM, Pintus G, Sarmento B, Giunchedi P, et al. Nose-to-brain delivery of BACE1 siRNA loaded in solid lipid nanoparticles for Alzheimer's therapy. Colloids Surf B Biointerfaces. (2017) 152:296301. doi: 10.1016/j.colsurfb.2017.01.031

98. Sonvico F, Clementino A, Buttini F, Colombo G, Pescina S, Stanisçuaski Guterres S, et al. Surface-modified nanocarriers for nose-to-brain delivery: from bioadhesion to targeting. Pharmaceutics. (2018) 10:34. doi: 10.3390/pharmaceutics10010034

99. Rassu G, Gavini E, Carta A, Obinu A, Porcu EP, Giunchedi P. Hydroxypropyl- $\beta$-cyclodextrin formulated in nasal chitosan microspheres as candidate therapeutic agent in Alzheimer's disease. Curr Drug Deliv. (2018) 15:746-8. doi: 10.2174/1567201814666171019104509

100. Carotenuto A, Costabile T, Moccia M, Falco F, Scala MR, Russo CV. Olfactory function and cognition in relapsing-remitting and secondaryprogressive multiple sclerosis. Mult Scler Relat Disord. (2019) 27:16. doi: 10.1016/j.msard.2018.09.024

101. Kondiah PP, Tomar LK, Tyagi C, Choonara YE, Modi G, du Toit LC, et al. A novel pH-sensitive interferon- $\beta$ (INF- $\beta$ ) oral delivery system for application in multiple sclerosis. Int J Pharm. (2013) 456:45972. doi: 10.1016/j.ijpharm.2013.08.038

102. Carroll EC, Jin L, Mori A, Muñoz-Wolf N, Oleszycka E, Moran HB, et al. The vaccine adjuvant chitosan promotes cellular immunity via DNA sensor cGAS-STING-dependent induction of type I interferons. Immunity. (2016) 44:597-608. doi: 10.1016/j.immuni.2016.02.004

103. Mudgal J, Mudgal PP, Kinra M, Raval R. Immunomodulatory role of chitosan-based nanoparticles and oligosaccharides in cyclophosphamidetreated mice. Scand J Immunol. (2019) 89:e12749. doi: 10.1111/sji.12749

104. Xiong $\mathrm{H}$, Wu M, Zou H, Jiang, S, Yi H, Yi T, et al. Chitosan inhibits inflammation and adipogenesis of orbital fibroblasts in Graves ophthalmopathy. Mol Vis. (2018) 24:509-17.

105. Li X, Dong W, Nalin AP, Wang Y, Pan P, Xu B, et al. The natural product chitosan enhances the anti-tumor activity of natural killer cells by activating dendritic cells. Oncoimmunology. (2018) 7:e1431085. doi: 10.1080/2162402X.2018.1431085

106. Das I, Padhi A, Mukherjee S, Dash DP, Kar S, Sonawane A. Biocompatible chitosan nanoparticles as an efficient delivery vehicle for Mycobacterium tuberculosis lipids to induce potent cytokines and antibody response through activation of $\gamma \delta \mathrm{T}$ cells in mice. Nanotechnology. (2017) 28:165101. doi: 10.1088/1361-6528/aa60fd

107. Brodaczewska K, Wolaniuk N, Lewandowska K, DonskowŁysoniewska K, Doligalska M. Biodegradable Chitosan decreases the immune response to trichinella spiralis in mice. Molecules. (2017) 22:2008. doi: 10.3390/molecules22112008

108. Wang Y, Tan H, Hui X. Biomaterial scaffolds in regenerative therapy of the central nervous system. Biomed Res Int. (2018) 2018:7848901. doi: 10.1155/2018/7848901

Conflict of Interest: JM-G receives honoraria from the journal Neurologia as editor-in-chief and has received personal consultancy fees from Lilly.

The remaining authors declare that the research was conducted in the absence of any commercial or financial relationships that could be construed as a potential conflict of interest.

Copyright (c) 2020 Matías-Guiu, Matías-Guiu, Montero-Escribano, Barcia, CanalesAguirre, Mateos-Diaz and Gómez-Pinedo. This is an open-access article distributed under the terms of the Creative Commons Attribution License (CC BY). The use, distribution or reproduction in other forums is permitted, provided the original author(s) and the copyright owner(s) are credited and that the original publication in this journal is cited, in accordance with accepted academic practice. No use, distribution or reproduction is permitted which does not comply with these terms. 